\title{
A PERSPECTIVA FUNCIONAL DA POSSE AGRÁRIA NO ATUAL ESTADO DEMOCRÁTICO DE DIREITO
}

\section{THE FUNCTIONAL PERSPECTIVE OF THE AGRARIAN POSSESSION IN THE CURRENT DEMOCRATIC RULE OF LAW}

\author{
Antonio Sergio Cordeiro Piedade ${ }^{1}$ \\ Sandra Nalú de Carvalho Campos Almeida ${ }^{2}$
}

\section{RESUMO}

Este artigo, através do método de pesquisa bibliográfico, aborda a posse agrária, cuja perspectiva funcional é analisada em face do atual Estado Democrático de Direito. A partir de prévia e breve abordagem do direito de propriedade privada, passa-se a construir o instituto da posse agrária de forma autônoma, com fundamento nas teorias sociológicas, considerando também as teorias clássicas. A releitura da posse agrária, de acordo com os respectivos valores sociais, autoriza a concepção da função social da posse agrária que, ao ser observada, recebe tutela jurídica e, por conseguinte, concorre para o alcance dos objetivos da República Federativa do Brasil.

Palavras-chave: Direito Agroambiental. Direito Agrário. Posse Agrária. Funcionalidade.

\begin{abstract}
This article, through bibliographic research, discusses the agrarian possession, whose functional perspective is analyzed in light of the current Democratic Rule of Law. From the previous and brief overview of the private property rights, the agrarian possession institute is built autonomously, based on sociological theories, also considering the classical theories. The rereading of agrarian possession, according to the respective social values, authorizes the conception of the social function of agrarian possession which, when observed, receives legal

\footnotetext{
${ }^{1}$ Doutor e Mestre em Direito pela Pontifícia Universidade Católica de São Paulo - PUC/SP Universidade Católica de São Paulo - (Brasil). Professor Adjunto da Faculdade de Direito da Universidade Federal de Mato Grosso. Promotor de Justiça do MP/MT.

${ }^{2}$ Mestranda em Direito Agroambiental pela Universidade Federal de Mato Grosso, UFMT, Mato Grosso. (Brasil). Analista Judiciário do Tribunal Regional Eleitoral de Mato Grosso.

E-mail: sandranalu10@gmail.com
} 
protection and, consequently, contributes to the achievement of the objectives of the Federative Republic of Brazil.

Keywords: Agro-environmental Law. Agrarian Law. Agrarian Possession. Functionality.

\section{INTRODUÇÃO}

A posse agrária é concebida pela atual ordem jurídica como valor de uso social, posto que deve cumprir uma função, um serviço em benefício da coletividade, uma vez que fundamentada no trabalho produtivo da terra e ocasionada pelos princípios que conduzem o Estado Democrático de Direito. Apesar de não se contrapor à posse civil, distingue-se dela, com características jurídicas específicas e contornos próprios, tratando-se de realidade social e jurídica.

É através da atividade agrária que essa espécie de posse se exterioriza, ou seja, por intermédio de uma série de atos do possuidor inclinados à exploração econômica da terra, com a finalidade de produzir frutos e auferir lucro para consumo próprio e da coletividade.

Nesta perspectiva, afirma-se que a expressão função social, apesar de frequentemente usada como legitimadora e qualificativa da propriedade, não pode ser atribuída apenas ao domínio.

A função sócio-econômica e ambiental da terra reside principalmente na posse, cuja ilação se afere a partir da dinâmica do uso dos bens imóveis.

Não obstante a Constituição da República e a legislação infraconstitucional não serem expressas acerca da posse agrária funcional, os elementos para assim adjetivar a relação de fato entre sujeito e coisa estão presentes na ordem jurídica vigente, inclusive constitucional, oportunizando o emprego da locução função social da posse.

Assim, para o desenvolvimento do tema foi realizada uma breve análise da propriedade segundo seus critérios ortodoxos e sua evolução, seguida da consideração e cotejo das teorias justificadoras da posse, clássicas e sociológicas, para então abordar a estrutura da posse agrária de forma autônoma, possibilitando sua releitura à luz dos valores constitucionais. 


\section{A POSSE E A PROPRIEDADE}

A abordagem da posse agrária requer uma prévia e breve análise do instituto da propriedade, especialmente porque pretende-se demonstrar que a atual ordem jurídica nacional não mais concebe a posse como mera exteriorização da propriedade, principalmente porque "cronologicamente a propriedade começou pela posse" (FACHIN, 1988, p. 13).

A posse dotada de autonomia se dissocia da propriedade, desligando-se desta, constituindo, portanto, uma nova situação jurídica, configurando-se a causa e a necessidade do direito de propriedade, além de seu conteúdo, conforme leciona Luiz Edson Fachin (1988, p. 13):

À medida em que a posse qualificada instaura nova situação jurídica, observa-se que a posse, portanto, não é somente o conteúdo do direito de propriedade, mas sim, e principalmente, sua causa e necessidade. Causa porque é sua força geradora. Necessidade porque exige sua manutenção sob pena de recair sobre aquele bem a força aquisitiva.

Por sua vez, enquanto direito subjetivo, a propriedade traduz uma relação jurídica de ingerência, estabelecida entre o titular do bem e a coletividade, que deve respeitá-la.

Segundo afirmam Cristiano Chaves de Farias e Nelson Rosenvald (2009, p. 168) "a propriedade não é o retrato material do imóvel com as características físicas, mas a feição econômica e jurídica que a representa formalmente", estando instrumentalizada pelo domínio, o que implica na possibilidade do proprietário exercer os atributos de usar, gozar, dispor e reivindicar a coisa, submetida ao seu poder.

A rigor, a posse não se confunde com a propriedade uma vez que se caracteriza em uma relação fática, estabelecida entre a pessoa e a coisa, podendo aquela ser proprietária ou não.

Desse modo, estando o estudo da posse relacionado com a compreensão do fenômeno da propriedade, a análise de ambos os institutos se mostra imprescindível à concepção do princípio da função social da posse agrária, cujas implicações concorrem para o atingimento dos objetivos do atual Estado Democrático de Direito, razão pela qual passa-se à abordagem do instituto da propriedade. 
A Constituição da República (BRASIL, 1988) ${ }^{3}$ vigente dispensa tratamento à propriedade privada de direito fundamental, conforme previsto no artigo $5^{\circ}$, inciso XXII, e como princípio da ordem econômica, nos termos do artigo 170, inciso II, condicionando-a, nos dois casos ao cumprimento da função social (artigo $5^{\circ}$, inciso XXIII e artigo 170, inciso III).

Nesta perspectiva constitucional, Ricardo Aronne (1999, p. 163) afirma a dupla intervenção estatal no direito de propriedade assinalando que:

Tal limitação decorrente é intrínseca ao instituto em pauta, sendo, portanto, interna ao mesmo. Distinguem-se duas intervenções no direito de propriedade, fruto da função social. A primeira, tem cunho limitador de tal direito, de modo que seu exercício ou oponibilidade não se revele prejudicial à pluralidade da coletividade. A segunda intervenção é impulsionadora, intervindo de modo ativo, para que da propriedade derive um resultado socialmente valioso.

Essa nova leitura dos institutos do direito civil que, permeados pelo direito constitucional, publicitam espaços classicamente privados, ocasionam restrições em seu aspecto individualista, que constitui sua característica.

Neste sentido, Ricardo Aronne (1999, p. 164-165) pontua:

O novo contorno dado ao direito de propriedade foge do domínio do direito privado, imiscuindo-se no direito público, como em nossa época vem ocorrendo no Direito como um todo, bem como, à luz da visão sistemática da ciência jurídica contemporânea, traz dinamicidade ao instituto em tela, ante os conceitos abertos que decorrem dos princípios que concorrem relativizando-se consoante o caso concreto. O Direito Civil resta constitucionalizado, "publicizado", por se alimentar de valores que fogem de sua regulação e o imbricam em um sentido de coletividade e cidadania, classicamente inconcebíveis na espécie.

Verifica-se, portanto, que, anteriormente, a propriedade tinha uma concepção claramente individual, com caráter absoluto e intangível, sendo que, atualmente, nos termos da Constituição da República, se socializou ao conciliá-la à função social, exigindo da ordem jurídica uma sequência legislativa e interpretativa compatível com a harmonização dos dois institutos fundamentais. Aos poucos, o caráter absoluto foi sendo suplantado, "desde a aplicação da teoria do abuso do direito, do sistema de limitações negativas e depois também das imposições positivas, deveres e ônus, até chegar-se à concepção da propriedade como função social"' (SILVA, 2010, p. 272).

\footnotetext{
${ }^{3}$ As demais referências ao texto constitucional brasileiro terão a mesma fonte, pelo que se escusa citá-la novamente.
} 
José Afonso da Silva (2010, p. 273) adverte que "a função social é elemento da estrutura e do regime jurídico da propriedade; é, pois, princípio ordenador da propriedade privada, incide no conteúdo do direito de propriedade; impõe-lhe novo conceito". De acordo com o autor, a concepção civilista do direito à propriedade é considerada limitada para os dias atuais diante dos preceitos da Constituição da República que estabelece seu regime fundamental, relegando para o Direito Civil reger tão somente as relações civis dela decorrentes.

Segundo Kildare Gonçalves de Carvalho (2009, p. 801) o princípio da função social incide sobre a estrutura e o conteúdo do direito de propriedade, além de constituir elemento qualificador da situação jurídica em questão, condicionando os modos de aquisição, uso, gozo e disposição dos bens. Ao assinalar que o postulado não envolve apenas limitação de exercício das faculdades do proprietário inerentes ao domínio, o autor conclui que:

A função social da propriedade introduz, na esfera endógena do direito, um interesse que pode até mesmo não coincidir com o do proprietário, com o predomínio do social sobre o individual, fenômeno denominado de socialidade. (CARVALHO, 2009, p. 801).

Assim, a função social constitui o princípio ordenador da propriedade privada, configurando-se como elemento da estrutura interna do regime jurídico da propriedade privada ao superar o aspecto excludente do individualismo. Mesmo que não seja da vontade do proprietário, o uso da propriedade requer a utilização de seus poderes e faculdades objetivando a realização do bem comum.

Por sua vez, na ordem econômica, a Constituição da República erigiu a propriedade privada relacionada à função social como princípio com o intuito de assegurar a todos a existência digna, segundo os ditames da justiça social, indicando os critérios passíveis de identificar a função social na propriedade urbana (artigo $182, \S 2^{\circ}$ ) e na propriedade rural (artigo 186), ambos inseridos no Título VII denominado Da Ordem Econômica e Financeira.

De acordo com o artigo 186 da Constituição da República, a função social da propriedade rural é cumprida quando, segundo critérios e graus de exigência estabelecidos em lei, atender, simultaneamente, os requisitos de aproveitamento racional e adequado da propriedade; de utilização adequada dos recursos naturais disponíveis e preservação do meio ambiente; de observação das normas que regem as relações de trabalho e de exploração favorável ao bem-estar dos proprietários e dos trabalhadores. 
Analisando o disposto na Constituição da República, Eros Roberto Grau (2005, p. 245) afirma que "a função social da propriedade atua como fonte da imposição de comportamentos positivos - prestação de fazer, portanto, e não meramente, de não fazer - ao detentor do poder que deflui da propriedade".

Antes da Constituição da República, o Estatuto da Terra (Lei nº 4.504/64) (BRASIL, $1964)^{4}$, no seu artigo 12 , positivou o princípio da função social da propriedade dispondo que "à propriedade privada da terra cabe intrinsecamente uma função social e seu uso condicionado ao bem-estar coletivo previsto na Constituição Federal e caracterizado nesta lei", atribuindo ao poder público, no seu artigo 13, o dever de promover de forma gradativa a extinção das formas de ocupação e de exploração da terra que contrariem sua função social.

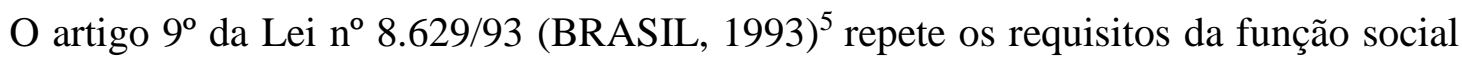
ao estabelecer em seus parágrafos os respectivos contornos nos seguintes termos:

\begin{abstract}
Art. $9^{\circ}$. [...]
$\S 1^{\circ}$. Considera-se racional e adequado o aproveitamento que atinja os graus de utilização da terra e da eficiência na exploração especificados nos $\S \S 1^{\circ}$ a $7^{\circ}$ desta lei.

$\S 2^{\circ}$. Considera-se adequada a utilização dos recursos naturais disponíveis quando a exploração se faz respeitando a vocação natural da terra, de modo a manter o potencial produtivo da propriedade.

$\$ 3^{\circ}$. Considera-se preservação do meio ambiente manutenção das características próprias do meio natural e da qualidade dos recursos ambientais, na medida adequada à manutenção do equilíbrio ecológico da propriedade e da saúde e qualidade de vida das comunidades vizinhas.

$\S 4^{\circ}$. A observância das disposições que regulam as relações de trabalho implica tanto o respeito às leis trabalhistas e aos contratos coletivos de trabalho, como à disposições que disciplinam os contratos de arrendamento e parcerias rurais.

$\S 5^{\circ}$. A exploração que favorece o bem-estar dos proprietários e trabalhadores rurais é a que objetiva o atendimento das necessidades básicas dos que trabalham na terra, observa as normas de segurança do trabalho e não provoca conflitos e tensões sociais no imóvel.
\end{abstract}

A função social da propriedade consta no Código Civil (BRASIL, 2002) ${ }^{6}$ sob forma de cláusula geral, conforme se depreende do $\S 1^{\circ}$ do artigo 1228 , donde se extrai que:

Art. 1228. [...]

$\S 1^{\circ} \mathrm{O}$ direito de propriedade deve ser exercido em consonância com as suas finalidades econômicas e sociais e de modo que sejam preservados, de conformidade com o estabelecido em lei especial, a flora, a fauna, as belezas

\footnotetext{
${ }^{4}$ As demais referências ao texto legal terão a mesma fonte, pelo que se escusa citá-la novamente.

${ }^{5}$ As demais referências ao texto legal terão a mesma fonte, pelo que se escusa citá-la novamente.

${ }^{6}$ As demais referências ao texto legal terão a mesma fonte, pelo que se escusa citá-la novamente.
} 
naturais, o equilíbrio ecológico e o patrimônio histórico e artístico, bem como evitada a poluição do ar e das águas.

Assim, da atual ordem jurídica nacional infere-se que a propriedade privada, tendo seu conceito jurídico-positivo integrado pelo princípio da função social, apresenta um rompimento da concepção tradicional de que a sua garantia reside em um direito absoluto e intangível, o que implica em atribuir à função social o exercício do papel de justificadora e legitimadora da propriedade.

Partindo desta concepção, André Ramos Tavares (2006, p. 297) afirma:

A propriedade privada é considerada como elemento essencial ao desenvolvimento do modelo capitalista de produção, e, ademais, o direito à propriedade é inafastável da concepção de democracia atualmente existente. Foi por esse motivo que se preservou o direito de propriedade, alterando-selhe o conteúdo, com a consagração de direitos sociais, e, ainda, com a declaração expressa de que também a propriedade é alcançada pela concepção social do Direito, o que se dá pela determinação de que a propriedade cumprirá sua função social.

Diante do que foi exposto, conclui-se que a ordem jurídica atual, consubstanciada nos termos do Estado Democrático de Direito previsto na Constituição da República, tutela a propriedade privada que cumpre a função social.

Ocorre que o cumprimento da função social dos imóveis agrários está na posse, ou seja, a função social da propriedade tem, como critério de aferição, a posse, uma vez que esta consiste num poder de ingerência econômica sobre determinada coisa, ou seja, um fato.

Somente através do exercício da posse é possível conferir função social à propriedade e conforme será constatado, nem sempre a posse está contida no domínio, sendo possível a posse agrária cumprir a função social ainda que desvinculada do domínio, galgando à posse um papel de maior relevo em relação à propriedade.

\section{O INSTITUTO DA POSSE}

O debate sempre norteou a posse, eis que poucos temas foram tão discutidos como este instituto, quer em relação a seus elementos, quer no tocante a sua origem, conceito, natureza e efeitos, podendo ser considerado um tema bastante controvertido, conforme assinala Sílvio de Salvo Venosa (2003, p. 44). 
Inicialmente, a humanidade concebia a posse do imóvel rural de maneira coletiva e social, isto é, sobre o imóvel rural não recaia uma compreensão capitalista, sendo considerada um produto dos deuses pagãos ou então da criação de um Deus cristão, criador de tudo e de todos, razão pela qual não era passível de apropriação pelos seres humanos mortais.

Perpassando as primeiras acepções divinas, o ser humano iniciou a tratar a posse e compreendê-la através de novas concepções, sendo provável que o primeiro documento legal que abrigou a posse subsumindo-a à propriedade tenha origem no Código de Hamurabi, por volta do século XVIII a. C.. Também já havia um debate sobre propriedade, por influência dos plebeus de Roma, na Lei das XII Tábuas.

Contudo, foi a partir do século XVII e, intensamente, no século XVIII d. C., que os debates ardorosos sobre posse e propriedade, especialmente, no imóvel rural, ganharam espaços nos cenários jurídicos e filosóficos.

$\mathrm{Na}$ Europa, fazendo surgir uma nova compreensão sobre a relação da terra com o ser humano, os cercamentos ou enclousure passaram a integrar o imóvel rural, podendo ser considerado um marco histórico ocidental para o entendimento do antigo sistema agrário de produção e sua evolução para o modo capitalista, especialmente nos campos ingleses, onde permitiram a migração de muitas pessoas para os centros urbanos em busca de trabalhos nas indústrias inglesas, bem como estimularam a vinda de colonos ingleses para o novo mundo, em decorrência da dificuldade para o acesso à terra dessas pessoas, o que gerou conflitos agrários.

Ainda em terreno europeu, as teorias civilistas defendidas por Savigny e Jhering ganharam destaque no cenário jurídico que, sob influência do direito romano, debateram em torno da fixação do conteúdo da posse e da sua proteção, a partir da análise dos elementos integrantes elencados como essenciais.

Em razão de tais teorias terem sido desenvolvidas em função da propriedade, objetivando mais a proteção desta que a posse, diante das mudanças sofridas na sociedade e no contexto científico do Direito, as mesmas ficam aquém das novas realidades vivenciadas nos dias atuais, apresentando-se como desatualizadas, apesar da importância de ambas em buscar um fundamento autônomo para a proteção possessória. Ademais, as teorias sociológicas sofrem grande influência da alguma das teorias clássicas, conforme adiante será abordado. 
Por sua vez, a evolução histórica do Brasil permite compreender a importância da posse que, passando pelas capitanias hereditárias, em seguida, pelas sesmarias e lei de terras, para adentrar na fase monárquica até a fase republicana, sempre esteve em contato com conflitos agrários que meneavam a questão da posse e da propriedade do imóvel rural.

Inúmeros conflitos agrários fundamentaram a evolução histórica e conceitual da posse e da própria propriedade do imóvel rural, sendo que muitos pensadores modernos refletiram sobre o tema escrevendo obras para entendê-la, assim como o filósofo John Rawls que argumentou sobre princípios de justiça, tais como igualdade de oportunidade no acesso à terra e às condições de vida, dando ênfase à ideia de justiça social, ganhando notabilidade no ambiente acadêmico americano.

Antonio José de Mattos Neto (1988, p. 15), destacando a característica polissêmica da palavra posse, assinala que ela "exprime a ideia de permanência sobre uma coisa por aquele que a tem como se sua fosse".

Atualmente, prevalece o entendimento que a posse se trata de um fato, consistente num poder de ingerência econômica sobre determinada coisa (RUGGIERO, 1999, p. 738739), e sob o aspecto normativo, encontra-se disciplinada nos artigos 1.196 a 1.124, no Livro III da parte especial do Código Civil brasileiro, que trata do Direito das Coisas, não tendo sido elencado o instituto em questão no rol de direitos reais do artigo 1.225 do indigitado diploma legal.

Considerando o atual modelo estatal denominado Estado Democrático de Direito e a expressividade do contexto da hermenêutica constitucional, diante dos valores jurídicos vigentes, com destaque para o princípio da dignidade da pessoa, a releitura do instituto da posse se impõe perante os objetivos traçados no artigo $3^{\circ}$ da Constituição da República.

Sem contrariar as teorias clássicas, o sistema apresentado convive com as teorias sociológicas que ostentam outras justificativas e elementos ao instituto da posse, razão pela qual é necessária a abordagem prévia das teorias clássicas de Savigny e Ihering para a compreensão dos contornos das teorias contemporâneas do instituto. 


\section{AS TEORIAS JUSTIFICADORAS DA POSSE}

Dentre as teorias clássicas justificadoras da posse foram desenvolvidas a teoria subjetiva por Frederich Karl Von Savigny e a teoria objetiva por Rudolph Von Ihering, cujos teóricos se basearam nos conhecimentos deixados pelos romanos.

Frederich Karl Von Savigny entendeu a posse como o "poder de dispor fisicamente de uma coisa, combinado com a convicção do possuidor de que tem esse poder." (BESSONE, 1996, p. 47).

Segundo a teoria subjetiva, dois elementos são imprescindíveis à configuração da posse, o elemento material, denominado corpus, caracterizado pelo fato físico/exterior que se revela mediante a possibilidade de disposição física da coisa, com exclusão de qualquer outro; e o elemento subjetivo, denominado animus domini, identificado como a vontade determinada que consiste na intenção de ter a coisa como sua, traduzida, portanto, na convicção do possuidor neste sentido. Inexistindo o animus, recairia sobre a coisa apenas a mera detenção.

Objetivando-se a prevenção da justiça pelas próprias mãos e da violência física contra a pessoa que tem a possibilidade física de dispor da coisa, a teoria subjetiva desenvolvida por Frederich Karl Von Savigny apresenta a paz social e a negação da violência como justificativas para a defesa da posse. Nesta concepção, quanto à natureza jurídica, a posse se apresenta como fato, pois independe do ordenamento jurídico, e como direito, considerando os efeitos que produz.

Cristiano Chaves de Farias e Nelson Rosenvald (2009, p. 32), acerca da natureza jurídica dúplice da posse para a teoria subjetiva, registram:

Para a teoria subjetiva, a posse teria a natureza jurídica dúplice. Em princípio seria mera situação fática. Considerada isoladamente, a posse é um fato, pois sua existência independe das regras de direito. Mas certas condições atribuem a este fato os efeitos de um direito pessoal, por produzir consequências jurídicas (v. g. usucapião e ações possessórias). Por esta visão combinada de posse como fato e direito, a lição de Savigny denominou-se teoria eclética. Savigny sustenta a tutela possessória no acautelamento da pessoa humana, que merece ser protegida de toda a forma de violência como conduta antijurídica.

Conforme observa José Carlos Moreira Alves (1997, p. 224), a análise sobre a posse realizada por Frederich Karl Von Savigny foi precedida por Donelo que, de forma 
semelhante, acentuou que, para possuir, são necessários os elementos: a detentio e o animus domini. Tal fato foi assinalado por Rudolph Von Ihering ao desenvolver a teoria objetiva, tecendo críticas à teoria subjetiva no que se refere à localização do elemento subjetivo, entretanto, referida constatação não tem o condão de desvalorizar a obra de Frederich Karl Von Savigny, que considera a posse uma relação de natureza pessoal, além de reduzi-la a uma autonomia mínima em relação à propriedade.

Nesta perspectiva, não é possível dissociar a teoria de Frederich Karl Von Savigny da formação da concepção da autonomia da posse frente à propriedade, consoante apontado por José Carlos Moreira Alves (1997, p. 222), ao citar a obra de Hernandez Gil:

Ao inquirir o significado autônomo da posse, Savigny não desconhece que pode apresentar-se como emanação do direito de propriedade (ius possidendi). O que afirma é a existência, ademais, de uns direitos estrita e exclusivamente derivados da posse (ius possessionis). Só o ius possessionis faz parte da teoria possessória propriamente dita. A posse ocupa uma posição equidistante da propriedade e da mera detenção. Da primeira se diferencia na mesma medida em que se contrapõem o fato e o direito; quanto à segunda, a distinção se põe em produzir, ou não efeitos jurídicos.

No mesmo sentido são as lições de Cristiano Chaves de Farias e Nelson Rosenvald (2009, p. 28-29) que constatam a relevância da teoria de Frederich Karl Von Savigny ao dotar a posse de autonomia em relação à propriedade, pois a concebe como uma situação fática digna de tutela, considerando-a como um fato na origem e um direito nas consequências.

Por outro lado, Rudolph Von Ihering, opondo-se de forma enfática à Frederich Karl Von Savigny, consolida sua teoria, denominada objetiva, posicionando a posse como a aparência/exteriorização do direito de propriedade que, em razão disso, passa a ser tutelada, ou seja, a proteção da posse ocorre em função da sua representatividade.

De acordo com a teoria objetiva desenvolvida por Rudolph Von Ihering, o elemento formador da concepção de posse consiste apenas no corpus, caracterizado pela prática de atos do proprietário pela pessoa que detém o bem, mesmo que não seja o titular, apresentando-se o elemento anímico, animus domini, inserto no corpus, prescindido-se de uma relação de apropriação física, mas econômica. Portanto, para compreender que existe posse é necessário o simples poder físico sobre a coisa com a intenção de permanência sobre ela, cuja conduta deve ser analisada objetivamente sem que se averigue a respeito da intenção do agente.

Neste sentido, Carlos Roberto Gonçalves (2012, p. 51) assinala: 
Tem posse quem se comporta como dono, e nesse comportamento já está incluído o animus. $\mathrm{O}$ elemento psíquico não se situa na intenção de dono, mas tão somente na vontade de agir como habitualmente o faz o proprietário (affectio tenendi) independentemente de querer ser dono (animus domini).

A conduta de dono pode ser analisada objetivamente, sem a necessidade de pesquisar-se a intenção do agente. A posse, então, é a exteriorização da propriedade, a visibilidade do domínio, o uso econômico da coisa. Ela é protegida, em resumo, porque representa a forma como o domínio se manifesta.

Para Rudolph Von Ihering tudo gira em torno da propriedade (FACHIN, 1988, p. 27), sendo a proteção possessória necessária porque a posse é complemento da propriedade, encontrando-se a defesa da posse sua justificativa na defesa da propriedade. Segundo a teoria objetiva, "a posse não é protegida por ser um poder jurídico, mas por ser um fato, que tem aparência de propriedade.” (BESSONE, 1996, p. 15)

Considerada como fundamento de um direito pelo teórico, a posse se configura como um direito subjetivo de natureza real, pertencendo ao direito das coisas, pois apresenta-se como uma relação imediata da pessoa com a coisa.

Como se pode notar, a polêmica existente entre as teorias clássicas reside nos elementos formadores da concepção da posse, o que, por sua vez, interfere na sua natureza, conforme exposto.

Por sua vez, o instituto da posse recebe novos rumos devido as alterações ocorridas na estrutura social e a contribuição de juristas sociólogos, levando-a à aquisição de uma posição independente face à propriedade.

Carlos Roberto Gonçalves (2012, p. 56) registra o fortalecimento da posse como reflexo da atual ordem jurídica e das novas teorias nos seguintes termos:

Essas novas teorias, que dão ênfase ao caráter econômico e à função social da posse, aliadas à nova concepção do direito de propriedade, que também deve exercer uma função social, como prescreve a Constituição da República, constituem instrumento jurídico de fortalecimento da posse, permitindo que, em alguns casos e diante de certas circunstâncias, venha a preponderar sobre o direito de propriedade.

Dentre os juristas sociólogos que trazem novas teorias justificadoras da posse que, a partir das estruturas sociológicas inseridas na configuração da propriedade privada conferem destaque ao caráter econômico e à função social da posse, encontram-se Silvio Perozzi, Raymond Saleilles e Antonio Hernández Gil. 
Ao formular a teoria social da posse Silvio Perozzi aponta como característica a passividade dos sujeitos da coletividade em relação à posse, ou seja, a abstenção de terceiros diante de tal fato.

A teoria da apropriação econômica foi apresentada por Raymond Saleilles que, arrimada na teoria objetiva de Rudolph Von Ihering com uma perspectiva diversa, sustenta que "a posse é relação de apropriação econômica, e não de relação de apropriação jurídica." (ALVES, 1997, p. 236). De acordo com o teórico, a apropriação econômica consciente e querida das coisas caracteriza a posse.

Antonio Hernández Gil, a partir da contribuição de cada uma das teorias para a consagração da teoria social da posse, assegura o êxito da autonomia da posse em relação à propriedade, ao asseverar que a função social opera como pressuposto e como fim das instituições reguladas pelo direito, perpassando pela posse a necessidade e o trabalho que são as grandes coordenadas da ação prática humana.

Luis Edson Fachin (1988, p. 27) assinala que o jurista espanhol resgata a teoria subjetiva de Frederich Karl Von Savigny ao recobrar a proteção da pessoa como justificativa da tutela da relação possessória, sendo a pessoa o centro da posse:

Em Savigny, o professor Hernández Gil encontra ponto de vista racional e lógico, protegendo-se a posse porque toda pessoa deve ser protegida da violência, fazendo, com isso, que o centro da defesa possessória seja a pessoa. O ponto alto da concepção de Savigny é a redução da posse a um mínimo básico de autonomia frente à propriedade, revelando um avanço em relação à concepção então vigente emanada do Código Napoleônico.

Assim, conforme se constata, as teorias sociológicas fazem uma releitura da posse segundo os valores sociais que lhes são inerentes, considerando-a como um direito subjetivo provido de autonomia que, mediante a utilização concreta da coisa caracteriza um poder fático de ingerência socioeconômica sobre determinado bem da vida.

Segundo Carlos Roberto Gonçalves (2012, p. 56) a atual ordem jurídica nacional acompanha a perspectiva dessa nova concepção teórica:

Em nosso país, o grande passo na direção da concepção social da posse foi dado com a reafirmação, no inciso XXIII do art. $5^{\circ}$ da Constituição Federal de 1988, do princípio de que "a propriedade atenderá a sua função social", complementado pelas regras sobre a política urbana, atinentes à usucapião urbana e rural $(\mathrm{CF}$, arts. 183 a 191). 
Desse modo, embora o texto constitucional tenha expressamente empregado o termo função social apenas ao domínio, a dinâmica do uso dos bens imóveis implica aferir que a função sócio-econômica e ambiental localiza-se principalmente na posse, verificando-se que a mesma não é mera aparência ou sombra da propriedade, sendo digna de tutela uma vez que a função social da terra é apurada pela posse e não pela propriedade.

\section{A POSSE AGRÁRIA}

Especialmente em relação à segurança acerca da natureza jurídica do imóvel rural como bem de produção que certamente é, o fenômeno da posse deve ser concebido à luz de novos paradigmas, sob enfoque diverso, devendo-se lançar mão da principiologia do Direito Agrário que traça os contornos desta nova ordem, donde ressai que o imóvel rural configura um dos valores primordiais na avaliação das relações jurídicas que circundam a propriedade, atribuindo a forma e o conteúdo à posse agrária, além de refletir na conjugação dos fatores de produção econômica.

Getúlio Targino Lima (1992, p. 92) define posse agrária como:

[...] exercício direto, contínuo, racional e pacífico, pelo possuidor, da atividade agrária desempenhada sobre um imóvel rural, apto ao desfrute econômico, gerando a seu favor um direito de natureza real especial, de variadas consequências jurídicas e visando ao atendimento de suas necessidades sócio-econômicas, bem como as da sociedade.

De acordo com o conceito apresentado pelo jurista a posse agrária pressupõe o exercício da atividade agrária que é representada pela utilização de recursos naturais pelo homem com o propósito social e econômico, configurando-se, como exemplos, sob uma perspectiva ampla, a agricultura, a pecuária, o extrativismo, a agroindústria, a comercialização e transporte de produtos. E ainda, aponta como objeto da posse agrária "a terra, um pedaço de chão que, racionalmente explorado, produza os bens que lhe são inerentes e gere a favor do possuidor e da sociedade os benefícios econômicos e sociais desejados" (LIMA, 1992, p. 92).

Por sua vez, Antonio José de Mattos Neto (1988, p. 68), conjugando os elementos integrantes do exercício da atividade agrária de forma direta, contínua, racional e pacífica, conceitua posse agrária no seguinte sentido:

Posse agrária é o exercício direto, contínuo, racional e pacífico de atividades agrárias (propriamente ditas, vinculadas ou complementares, e conexas) desempenhadas em gleba de terra rural capaz de dar condições suficientes e 
necessárias ao seu uso econômico, gerando ao possuidor um poder jurídico de natureza real, definitiva, com amplas repercussões no Direito, tendo em vista o seu progresso e bem-estar econômico e social.

Assim, a configuração legítima da posse agrária implica no cultivo da terra, caracterizado pelo exercício da atividade agrária, cujos atos de domínio devem ser praticados pessoalmente pelo possuidor, acarretando a funcionalidade da terra, não se confundindo, portanto, com a posse civil.

Sob esta ótica, a propriedade apresenta-se como mera consequência da posse agrária, uma vez que a consolidação desta já se implementou com a atividade agrária desenvolvida prolongadamente pelo possuidor, o que revela a tutela do trabalho agrícola através da posse agrária e, com isso, ocasionando a valorização jurídica do trabalho, que é a razão da proteção possessória agrária.

De acordo com referido jurista, a terra "deve ser trabalhada, cultivada pelo homem, a fim de gerar riquezas em proveito próprio e da comunidade. " (MATTOS NETO, 1988, p. $45)$.

Acerca da caracterização da posse agrária, Antonio José de Mattos Neto (1988, p. 47) leciona:

Para a caracterização da posse agrária requer-se vinculação imediata do possuidor à terra. Diante deste quadro, podemos identificar os elementos estruturais da posse agrária. Evidentemente, ela é composta pelos dois elementos presentes em qualquer posse: corpus e animus. Diferencia-se da posse comum a partir do preenchimento desses conceitos.

O corpus, elemento objetivo, é traduzido por atos que exteriorizam a vinculação direta, material, imediata do possuidor da terra. A posse agrária exige uma apreensão imediata e direta sobre a coisa. A relação entre o homem e a terra é direta, física, revelada por atos materiais.

A exploração econômica da terra há de ser direta. O Direito Agrário condena o desfrute do imóvel rural como simples fonte de renda derivada do trabalho alheio.

$[\ldots]$

A lei agrária prestigia o rurícola que diretamente, através de seus próprios esforços e riscos, organiza empreendimento agrário, no intuito de produzir riquezas.

Desse modo, para a configuração do elemento objetivo corpus é necessária a associação direta e imediata do possuidor à terra, através dos fatores de produção, objetivando, através de atos materiais, o desenvolvimento da adequada e racional atividade agrária. 
Por sua vez, registre-se que em relação ao animus, o jurista observa que a intenção imediata de exercer o direito de propriedade como se fosse seu titular é prescindível, uma vez que "a intenção do possuidor agrário é de trabalhar a terra: pretende explorar economicamente a terra, produzindo bens consumíveis, para sobrevivência própria, da família e da comunidade, participando do processo produtivo". (MATTOS NETO, 1988, p. 47-48).

Assim, o elemento anímico é revelado pelo trabalho agrário que atinge seu objetivo com a consecução do resultado decorrente do exercício desta atividade.

A partir do que foi exposto, verifica-se que a distinção entre a posse agrária e a posse civil recai no fato de que a primeira está associada à idéia da produtividade e da pessoalidade do ato agrário, ou seja, é necessário que o verdadeiro possuidor esteja realmente na terra, cultivando-a para usufruir o que ela proporciona, não havendo lugar para a posse indireta, como ocorre na posse civil, sendo este, portanto, o principal contraste entre as duas concepções de posse sobre o imóvel rural.

A rigor, propriedade e a posse agrárias frequentemente se reúnem na pessoa de um mesmo titular, mas essa não é uma condição necessária uma vez que nem sempre a posse está contida no domínio. Da ordem jurídica infere-se que a propriedade é sempre um direito e a posse é um fato que pode ser ou não ser um direito. A posse agrária poderá existir sem a propriedade, daí vislumbra-se a importância da sua tutela, cuja implementação se verifica através de dispositivos constitucionais e infraconstitucionais.

É certo que a posse agrária, mesmo quando exercida pelo proprietário, deve ser encarada com autonomia, uma vez que o mesmo tanto pode praticar atos possessórios (uso, fruição, destinação etc), como atos estranhos à posse (alimentação, disposição, reivindicação etc). Por este ângulo, pertinente a afirmação de Luiz Edson Fachin de que, mesmo sendo exercida pelo proprietário, "a posse é um fato com algum valor jurídico" (FACHIN, 1988, p. 13).

À vista disso, a posse agrária tem autonomia e, portanto, produz reflexos, não se confundindo com a propriedade, mesmo se tratando de posse agrária do proprietário. Nesse sentido:

Gera a posse agrária considerável elenco de efeitos. Em se tratando de bem imóvel, tais resultados mais evidentes estão intimamente ligados à futura aquisição do instrumento formal da propriedade (título), indenização por benfeitorias e retenção da coisa e, finalmente, à defesa possessória. (LIMA, 1992, p. 93). 
A posse agrária destaca-se, no contexto social, ambiental e econômico, como elemento integrante do atual Estado Democrático de Direito, porque além de permitir a produção de riquezas para o possuidor e para a coletividade, oferece condições de dignidade ao possuidor. Assim, além de uma atividade produtora de riquezas, destina-se ao bem-estar do possuidor, da coletividade e da conservação ambiental, constituindo e materializando o disposto no artigo $3^{\circ}$ da Constituição da República que elenca os objetivos fundamentais da República Federativa do Brasil.

\section{DA FUNÇÃO SOCIAL DA POSSE AGRÁRIA}

Funcionar é produzir uma utilidade, é operar concretamente no mundo dos fatos, e a função social se verifica quando a coisa produz utilidade além do interesse do titular.

Como se viu, a posse agrária ultrapassa o mero poder físico sobre a coisa ou o exercício dos poderes inerentes à propriedade, uma vez que sua configuração pressupõe o exercício, por parte do possuidor, de uma atividade qualificada como agrária.

Nesta perspectiva Alcir de Gurcen Miranda (1992, p. 50) assinala que "Na posse agrária existe um vínculo físico real com a terra, através da atividade agrária que exerce sobre o imóvel rural, e qualquer interferência neste vínculo constitui agressão ao homem do campo".

Por sua vez, o $\S 1^{\circ}$ do artigo $2^{\circ}$ do Estatuto da Terra elenca os fatores que, simultaneamente, devem coexistir para que a propriedade da terra desempenhe integralmente a sua função social.

Descarte, sobre a terra recairão atividades que a farão produzir e frutificar uma vez que se trata de um bem de produção, cuja uso efetivo da posse se faz imprescindível como condição de seu reconhecimento no que diz respeito ao imóvel agrário.

No mesmo sentido, em relação aos requisitos que devem ser observados para que uma propriedade agrária cumpra a função social, dispõe o artigo 186 da Constituição da República.

$\mathrm{Na}$ atual ordem jurídica, pode-se afirmar que a função social da propriedade imóvel agrária está conexa ao aspecto produtivo, cuja implementação pressupõe a existência da posse, esteja esta na pessoa do titular da propriedade ou de outra pessoa, pois decorre de uma relação jurídica que envolve o homem, a coisa e o trabalho. É o que se depreende do $\S 1^{\circ}$ do artigo 1.228 do Código Civil. 
A exegese dos dispositivos constitucional e legais transcritos denota que a verificação do cumprimento da função social pela propriedade agrária repousa no uso da terra, ou seja, na finalidade que lhe confere o sujeito.

Por sua vez, a posse não é outra coisa senão o uso da terra, o contato com o solo. Os atos de posse, ainda que praticados pelo proprietário, revelam-se com a exploração econômica da terra, como a produção de frutos e a construção de benfeitorias e acessões, sendo a produtividade uma forma de possuir a terra.

Os pressupostos estabelecidos no artigo 186 da Constituição da República têm como foco a posse do proprietário e a posse do não proprietário, eis que não é necessário ser titular para conferir função à terra, mas ser possuidor é fundamental para tal desiderato.

A terra, sem a posse, não passa de uma reserva de valor descompromissada de objetivos funcionalizantes.

Desse modo, é através da posse agrária que a função social da terra deve ser conferida e aferida, residindo a função social, portanto, na posse agrária, o que implica concluir que a função social da posse agrária está implícita na função social da propriedade agrária.

A função social da posse está implícita nos artigos $5^{\circ}$, caput, incisos XXII, XXIII, XXIV, 170, 173, 182, 183, 184, 185, 186, 191 da Constituição da República e em diversos dispositivos do Código Civil, por exemplo, nos artigos 1.228, 1.238 e 1.242.

Sobre a função social da posse, Francisco Cardoso Oliveira (2006, p. 247) assevera:

É provável que para a Constituição a função social da posse esteja inserida na dinâmica da história e da sociabilidade que o ordenamento jurídico contempla e tutela na medida do seu acontecer. Mas é provável também que o texto constitucional tenha preferido tutelar de forma explícita a função social da propriedade, que é compatível com a existência do mercado e do sistema de trocas, e tenha evitado fazê-lo em relação à função social da posse para não correr o risco de revigorar o valor de uso em detrimento do valor de troca.

Assim, o fato da Constituição da República não tratar de forma explícita a função social da posse agrária não implica no impedimento para o seu reconhecimento, uma vez que, conforme demonstrado, a função social da terra é implementada e verificada através da posse, cujo objeto é o uso de um bem de produção destinado à produção de riquezas, ao bem-estar do possuidor, da coletividade e da conservação ambiental, concorrendo para o alcance dos valores previstos na Constituição da República. 


\section{A PERSPECTIVA FUNCIONAL DA POSSE AGRÁRIA COMO INSTRUMENTO DE REALIZAÇÃO DOS OBJETIVOS DO ATUAL ESTADO DEMOCRÁTICO DE DIREITO}

A propriedade e a posse agrárias são conformadas pelas dimensões apresentadas pelas constituições democráticas que delineam novo paradigma constitucional para que exerçam a função social que lhes é inerente, ex vi do artigo 186 da Carta Magna Brasileira.

A Constituição da República instituiu no artigo $1^{\circ}$, incisos III e IV, como fundamento da República Federativa do Brasil "a dignidade da pessoa humana" e os "valores sociais do trabalho e da livre iniciativa", sendo que no artigo $3^{\circ}$, incisos I, II e II, constam como seus objetivos fundamentais "constituir uma sociedade livre, justa e igualitária, garantir o desenvolvimento nacional e erradicar a pobreza e a marginalização e reduzir as desigualdades sociais e regionais".

Por seu turno, o texto constitucional elencou a função social da propriedade como um dos direitos e garantias fundamentais e também como um dos megaprincípios da ordem econômica (artigos, $5^{\circ}$, XXIII e 170, III) com o objetivo de promover a determinação de seu atendimento ao patamar de regra fundamental, criando um paradigma interpretativo do ordenamento jurídico, instrumentalizando-o.

Conforme visto, a posse exerce papel de destaque no Estado Democrático de Direito porque permite a produção de riquezas para o possuidor e para a coletividade, bem como oferece ao possuidor condições de viver com dignidade. Portanto, a atual ordem jurídica concebe a posse como uma atividade destinada à produção de riquezas, ao bem-estar do possuidor e da coletividade, assim como à conservação ambiental.

O Direito, abandonando a costumeira função repressiva, especialmente na relação do Direito com a Economia, interessa-se por funções distributivas e promocionais.

Neste sentido são as lições de Francisco dos Santos Amaral Neto (1989, p. 229):

Emprestar ao direito uma função social significa considerar que a sociedade se sobrepõe ao interesse individual, o que justifica acabar com as injustiças sociais. Função social significa não individual, sendo critério de valoração de situações jurídicas conexas ao desenvolvimento das atividades da ordem econômica. Seu objetivo é o bem-comum, o bem estar econômico coletivo. 
Sendo assim, a função social conforma internamente aos ditames constitucionais e modela a estrutura dos direitos à propriedade e posse agrárias, não limitando ou restringindo tais institutos externamente, com a finalidade de que proprietário, possuidor e terceiros materializem as normas constitucionais.

E, neste contexto, tendo o legislador como razão um ideal de ordem, prosperidade e paz, apresenta-se a posse agrária que, uma vez observada sua perspectiva funcional nos moldes previstos na Constituição da República e legislação infraconstitucional, recebe tutela jurídica concorrendo para o atingimento dos objetivos do atual Estado Democrático de Direito.

Desse modo, ao proteger a sociedade de interpretações que, sob o pálio de um eficiente desenvolvimento da sociedade, priorizam a suposta "eficiência" acarretada pela análise econômica do Direito, com base na maximização da riqueza e redução dos custos sociais, a posse agrária funcionalizada, concebida na ordem jurídica atual, com fundamento na dignidade da pessoa humana, efetiva os valores constitucionais da liberdade, justiça e solidariedade.

\section{CONSIDERAÇÕES FINAIS}

Conquanto a Constituição da República erige a propriedade privada ao patamar de direito fundamental e como princípio da ordem econômica, exige-se que, nas duas situações, o instituto cumpra função social para ser protegido pelo ordenamento jurídico.

Por sua vez, a função social da terra é atribuída e apurada através da posse que, nem sempre, está incorporada ao domínio, sendo possível a posse observar a função social independentemente da propriedade, devendo a posse existir e ser reconhecida de per si.

É evidente que a posse existe antes e independente da propriedade, e como tal deve ser tutelada, inclusive contra o proprietário, quando este não exerce efetivamente a posse nos termos das determinações constitucionais.

As teorias justificadoras da posse, clássicas e sociológicas, foram abordadas e cotejadas, demonstrando que a polêmica em torno da concepção da posse persiste até os dias atuais, contudo, apesar das divergências, todas convergem para dotá-la de uma autonomia, menor ou maior, em relação à propriedade. 
Nesta perspectiva, a posse agrária se apresenta com características específicas, cujo exercício implica no cultivo da terra, através do exercício da atividade agrária, pessoalmente, ocasionando a funcionalidade da terra e a consequente valorização jurídica do trabalho.

O fato do texto constitucional não veicular de forma expressa a função social da posse agrária não implica na vedação para o seu reconhecimento, pois a função social da terra é conferida e aferida por meio da posse, cujo objeto é o uso de um bem de produção destinado à produção de riquezas, ao bem-estar do possuidor, da coletividade e da conservação ambiental, estando, portanto, a função social da posse agrária implícita na função social da propriedade agrária.

Dessa forma, conclui-se que a posse agrária, desde que realizada sua perspectiva funcional nos moldes constitucionais, foi concebida pela ordem jurídica vigente como um dos instrumentos aptos ao alcance dos objetivos estatuídos pelo atual Estado Democrático de Direito, com fundamento na dignidade da pessoa humana, razão pela qual é tutelada constitucionalmente e pela legislação infraconstitucional com o fito de produzir os efeitos almejados pela República Federativa do Brasil.

\section{REFERÊNCIAS BIBLIOGRÁFICAS}

ALVES, José Carlos Moreira. Posse. V. I. Rio de Janeiro: Forense, 1997.

AMARAL NETO, Francisco dos Santos. A autonomia privada como princípio fundamental na ordem jurídica. Disponível em: https://www2.senado.leg.br/bdsf/bitstream/handle/id/181930/000444811.pdf?sequence=1. Acesso em 12 jul. 2016.

ARONNE, Ricardo. Propriedade e domínio. Reexame sistemático das noções nucleares de direitos reais. Rio de Janeiro: Renovar, 1999. 
BESSONE, Darcy. Da posse. São Paulo: Saraiva, 1996.

BRASIL. Constituição da República Federativa do Brasil: promulgada em 5 de outubro de 1988.

Disponível

em:

http://www.planalto.gov.br/ccivil_03/constituicao/constituicaocompilado.htm. Acesso em: 10 jul. 2016.

BRASIL. Lei $\mathbf{n}^{0}$ 4.504, de 30 de novembro de 1964. Dispõe sobre o Estatuto da Terra, e dá outras providências. Diário Oficial de União, Brasília, 30 nov. 1964. Disponível em: http://www.planalto.gov.br/ccivil_03/leis/L4504.htm. Acesso em: 10 jul. 2016.

BRASIL. Lei 8.629, de 25 de fevereiro de 1993. Dispõe sobre a regulamentação dos dispositivos constitucionais relativos à reforma agrária, previstos no Capítulo III, Título VII, da Constituição Federal. Diário Oficial da União, 26 fev 1993. Disponível em: http://www.planalto.gov.br/ccivil_03/leis/L8629.htm. Acesso em: 12 jun 2016.

BRASIL. Lei 10.406, de 10 de janeiro de 2002. Institui o Código civil. Diário Oficial da União, $11 \quad$ jan. $2002 . \quad$ Disponível em: http://www.planalto.gov.br/ccivil_03/leis/2002/110406.htm. Acesso em: 12 jun 2016.

CARVAlHO, Kildare Gonçalves. Teoria do Estado e da Constituição. Direito Constitucional Positivo. 15. ed. Belo Horizonte: Del Rey, 2009.

FACHIN, Luiz Edson. A função social da posse e a propriedade contemporânea: uma perspectiva da usucapião imobiliária rural. Porto Alegre: Sergio Antonio Fabris, 1988.

FARIAS, Cristiano Chaves de; ROSENVALD, Nelson. Direitos reais. 6. ed.. 2. Tir. Rio de Janeiro: Lumen Juris, 2009.

GONÇALVES, Carlos Roberto. Direito civil brasileiro. Direito das coisas. 7. ed. $2^{\mathrm{a}}$ Tir. São Paulo: Saraiva, 2012. 
GRAU, Eros Roberto. A ordem econômica na constituição de 1988 (interpretação e crítica). 10. Ed. São Paulo: Malheiros, 2005.

GURSEN MIRANDA, Alcir de. O instituto jurídico da posse agrária. Pará: CEJUP. 1992.

LIMA, Getúlio Targino. A posse agrária sobre bem imóvel: implicações no direito brasileiro. São Paulo: Saraiva, 1992.

MATTOS NETO, Antonio José de. A posse agrária e suas implicações jurídicas no Brasil. Pará: CEJUP, 1988.

OLIVEIRA, Francisco Cardozo. Hermenêutica e Tutela da Posse e Propriedade. Rio de Janeiro: Editora Forense, 2006.

RUGGIERO, Roberto de. Instituições de Direito Civil. V. 1. Trad. Paolo Capitano. 6. Ed. Campinas: Bookseller, 1999.

SILVA, José Afonso da. Curso de direito constitucional positivo. 33. Ed. São Paulo: Malheiros, 2010.

TAVARES, André Ramos. Curso de direito constitucional. 3 ed. São Paulo: Saraiva, 2006.

VENOSA, Sílvio de Salvo. Direito civil: direitos reais. Vol. 5. 3. ed. São Paulo: Editora Atlas, 2003. 